\title{
Epidemiological and clinical characteristics of cutaneous leishmaniasis and their relationship with the laboratory data, south of Brazil
}

\section{Authors}

Maura Cristiani de

Moura Curti ${ }^{1}$

Thaís Gomes

Verzignassi Silveira ${ }^{2}$

Sandra Mara Alessi

Aristides Arraes ${ }^{2}$

Dennis Armando Bertolini²

Paulo Donizeti Zanzarini ${ }^{3}$

Eneide Aparecida

Sabaini Venazzi ${ }^{1}$

Andrea Cláudia

Silva Fernandes ${ }^{1}$

Jorge Juarez Vieira Teixeira ${ }^{2}$

Maria Valdrinez

Campana Lonardoni ${ }^{2}$

${ }^{1}$ Master's Degree,

Universidade Estadual de

Maringá (UEM/LEPAC)

${ }^{2} \mathrm{PhD}, \mathrm{UEM} / \mathrm{LEPAC}$

${ }^{3}$ Specialist, UEM/LEPAC
Submitted on: 04/08/2010 Approved on: 07/02/2010

Correspondence to:

Maria Valdrinez Campana Lonardoni

Avenida Colombo, 5790

CEP 87020-900

Maringá - PR, Brasil

CEP: $87020-900$

mvclonardoni@uem.br

We declare no conflict of interest.

\begin{abstract}
Objective: To evaluate clinical, epidemiological and laboratorial aspects for the understanding of the disease characteristics and its relationship with diagnostic tests. Methods: A retrospective, descriptive and analytical study involving 2,660 American cutaneous leishmaniasis (ACL) suspected patients from southern Brazil was undertaken between April 1986 and December 2005. Data on population characteristics and laboratory tests were obtained. Diagnostic laboratory tests used were direct search for Leishmania spp. (DS), Montenegro skin test (MST) and indirect immunofluorescent assay (IFA). Results: $62.3 \%$ of patients were positive for at least one laboratory test. DS test was positive in $65.1 \%$; MST in $92.3 \%$ and IFA in $70.0 \%$. Although Cohen's Kappa test did not reveal any agreement with laboratory diagnosis for ACL, the association between MST and IFA tests increased positiveness to 98.9\%; MST and DS to $97.2 \%$; and IFA and DS to $85 \%$. IFA and MST positiveness were higher among patients with $\leq 2$-month lesion-evolution time. Most ACL patients were male (72.6\%) in the age range of 15-49 years, featuring lesions during two months or less (53.9\%) and a cutaneous form of the disease (88.0\%). Conclusion: Findings suggest that for the adequate identification of ACL cases a combination of laboratory tests that involves the association of MST with at least another test should be used.
\end{abstract}

Keywords: clinical laboratory techniques; disease transmission; infectious; cutaneous leishmaniasis; epidemiology.

[Braz J Infect Dis 2011;15(1):12-16]@Elsevier Editora Ltda.

\section{INTRODUCTION}

American cutaneous leishmaniasis (ACL) is transmitted by bites from insects of the Phlebotomine family, which inoculate the host's dermis with protozoa of the Leishmania genus and cause an ulcer on the site. When the species is Leishmania (Viannia) braziliensis, a mucocutaneous destructive lesion ensues in the nasooropharynx area. It has been observed that cutaneous ulcers, whether treated or not, tend to heal after several months. However, smooth and shiny scars, characterized as atrophic, hairless, and depressed with hypo- or hyper-pigmented areas, become residual. ${ }^{1}$ Although cases of relapse and/or progression to the mucocutaneous type may occur after treatment despite complete healing of the initial lesion, ${ }^{2-5}$ inadequate or incomplete treatment of the initial ulcer seems to be an important factor in its development. ${ }^{6-8}$

ACL occurs throughout the Americas, from southern United States to northern Argentina. The disease is found in almost all Latin American countries, with the exception of Chile and Uruguay. ${ }^{9}$ ACL is found in all Brazilian states and infects both sexes and all age brackets. ${ }^{10} \mathrm{~L}$. (V.) braziliensis is predominantly the ACL agent in the southern state of Paraná, with disease reported in 289 of the 399 municipalities. ACL has been reported in Paraná since the start of the 20th century when the region was settled by white people and the original forest was destroyed to make way for coffee, soya bean, wheat and other crops. However, remnants of original forest remain, especially in the neighborhood of many rivers and streams. In fact, they provide a favorable environment for wild animal species and other abundant vectors, reservoirs of Leishmania, throughout the state. ${ }^{10-11}$

Direct microscopy for parasite search in the lesions and the Montenegro skin test for hypersensitivity to Leishmania antigens are the most frequent tests for ACL laboratorial diagnosis. Serological tests, such as indirect immunofluorescent assay (IFA), enzyme immunoassay (EIA) and polymerase chain reaction (PCR), have produced satisfactory results. ${ }^{12-14}$ Direct search for parasites in 
lesions and the Montenegro skin test have been recommended at the Brazilian Public Health Centers, which, together with the clinical aspects of lesion and epidemiological antecedents, provide the basis for ACL diagnosis. ${ }^{15}$

In the current study, suspected ACL patients seen at a regional reference laboratory for diagnosing the disease were investigated to evaluate their clinical, epidemiological and laboratory aspects, and the relationship between disease's characteristics and diagnostic tests.

\section{MATERIAL AND METHODS}

\section{Area of study}

The state of Paraná lies in southern Brazil, with the Tropic of Capricorn passing throughout its northern region. In the current study, the municipalities lie in the state northwestern, northern-central north and western-central meso-regions. This vast region has been depleted of most of its native tropical and subtropical forests, with remnants of forest residues along the banks of large rivers and their tributaries, such as the Ivaí, Paraná and Paranapanema rivers. The region's population amounts to approximately 683,563 inhabitants and its economy is mainly based on agriculture and live-stock raising, with important secondary food, textile, confectionary and furniture industries producing sectors. Since the first decades of the 20th century the region has been settled by Italian, German, and Japanese immigrants and by migrants from other Brazilian states, such as São Paulo and Rio Grande do Sul, in search for land to plant coffee and, later, live-stock raising.

\section{Population}

Between April 1986 and December 2005, 2,660 suspected ACL patients were seen at the Laboratory of Teaching and Research in Clinical Analyses of the Universidade Estadual de Maringá (LEPAC/UEM), Maringá PR Brazil. The study included 1,656 patients with clinical diagnosis of ACL which had at least one positive laboratory test.

\section{Study design}

Analysis was retrospective, descriptive and information was obtained by means of a standardized epidemiological questionnaire filled in with the patients' details collected at the time of performing laboratory diagnostic tests.

\section{Variables of interest}

Gender, age, location of residence, duration and evolution of the lesion, type and location of lesions, and laboratory test results.

\section{Diagnostic techniques}

(I) Direct search for Leishmania spp. (DS): samples, collected from suspected patients, were obtained by the scraping of lesions. Glass slides were made from the material and stained with Giemsa. They were then examined under the mi- croscope for Leishmania spp.; (II) Montenegro skin test (MST): $0.1 \mathrm{~mL}$ of antigen (supplied by the Immunobiological Production and Research Centre - CPPI PR Brazil) was inoculated on the front side of the patient's forearm. The antigen suspension was composed of promastigote forms of $L$. (Leishmania) amazonensis in $40 \mu \mathrm{g} / \mathrm{mL}$ of protein nitrogen. Reading, undertaken 48-72h after inoculation, was positive when a $\geq 5 \mathrm{~mm}$ diameter cutaneous induration was present; ${ }^{16}$ and (III) Indirect immunofluorescent assay (IFA): serum samples were stored at $4^{\circ} \mathrm{C}$ until the tests were carried out, and at $-20^{\circ} \mathrm{C}$ thereafter. IFA technique for IgG antibodies was performed with promastigote forms of L. (V.) braziliensis. Serum was diluted from 1/20 in ratio 2, employing human anti-IgG-fluorescein isothiocyanate conjugate. Samples with titers $\geq 40$ were considered positive. ${ }^{16}$

\section{Statistical analysis}

Data were pooled and analyzed with Excel and Statistica 5.0. Chi-square and Mantel-Haenszel association tests were used to compare categorical variables. The significance level was 0.05 . Agreement beyond chance among tests was assessed by Cohen's Kappa Statistics ( $<0$ no agreement; 0-0.19 poor; 0.20-0.39 fair; 0.40-0.59 moderate; 0.60-0.79 substantial and $0.80-1.00$ almost perfect). ${ }^{17}$

\section{Ethical principles}

The current investigation was evaluated and approved by the Permanent Committee for Ethics in Research Involving Human Beings (COPEP) of the Universidade Estadual de Maringá. (Protocol 080/2006).

\section{RESULTS}

In the current study, out of 2,660 patients referred for laboratory tests $1,656(62.3 \%)$ with at least one positive laboratory test were selected. Specifically, DS technique was positive in $65.1 \%$ of the study sample; MST technique in $92.3 \%$; and IFA technique in $70.0 \%$.

When MST and DS tests were associated (Table 1), 59.4\% of the patients were positive for both tests. However, no agreement beyond chance between the two tests could be demonstrated (Kappa $=-0.00063 ; 95 \%$ CI: $-0.04438--0.03175)$. When IFA + DS tests were analyzed, $54.6 \%$ of patients were positive to both tests, featuring a fair agreement (Kappa $=0.2812 ; 95 \%$ CI: $0.2292-0.3331)$. Furthermore, MST + IFA tests showed that $62.3 \%$ of patients were positive to both tests, with no agreement (Kappa $=-0.07762$; 95\% CI: $-0.01138--0.00415)$. On the other hand, MST + IFA tests increased positiveness to $98.9 \%$, MST + DS to $97.2 \%$, and IFA + DS to $85 \%$.

Out of 1,656 patients with an ACL positive laboratory test (Figure 1), 39.4\% had positive results for the three tests. On the other hand, $31.4 \%$ had positive results in two tests, whereas $29.2 \%$ had only one positive test. In fact, 74.9\% MST-positive patients had also another positive test, and $92.1 \%$ of IFA-positive patients and $96.9 \%$ of DS-positive patients were positive for another test. 
Table 1. Results of the direct parasite search, Montenegro skin test and indirect immunofluorescent assay tests performed on American cutaneous leishmaniasis patients, Maringá - Paraná, Brazil, 1986-2005

\begin{tabular}{|c|c|c|c|c|}
\hline \multirow{2}{*}{ MST } & \multicolumn{2}{|c|}{ DS } & \multirow[t]{2}{*}{ Total } & \multirow{2}{*}{$\begin{array}{c}\text { Kappa statistic } \\
\text { (CI 95\%) }\end{array}$} \\
\hline & Positive & Negative & & \\
\hline Positive & 771 & 419 & 1,190 & 0.000631 \\
\hline Negative & 71 & 36 & 107 & 0.04438 \\
\hline Total & 842 & 455 & 1,297 & 0.03175 \\
\hline \multirow{2}{*}{ IFA } & \multicolumn{2}{|c|}{ DS } & \multirow{2}{*}{ Total } & \\
\hline & Positive & Negative & & \\
\hline Positive & 737 & 272 & 1,009 & 0.2812 \\
\hline Negative & 141 & 200 & 341 & 0.2292 \\
\hline Total & 878 & 472 & 1,350 & 0.3331 \\
\hline \multirow{2}{*}{ IFA } & \multicolumn{2}{|c|}{ MST } & \multirow{2}{*}{ Total } & \\
\hline & Positive & Negative & & \\
\hline Positive & 971 & 104 & 1,075 & 0.07762 \\
\hline Negative & 467 & 17 & 484 & 0.1138 \\
\hline Total & 1438 & 121 & 1,559 & 0.00415 \\
\hline
\end{tabular}

DS, direct search; MST, Montenegro skin test; IFA, indirect immunofluorescent; CI, confidence interval.

Figure 1: Combined results of the laboratory tests performed on the 1,656 patients with positive diagnosis of American cutaneous leishmaniasis in the period from 1986 to 2005 in Maringá - Paraná, Brazil.

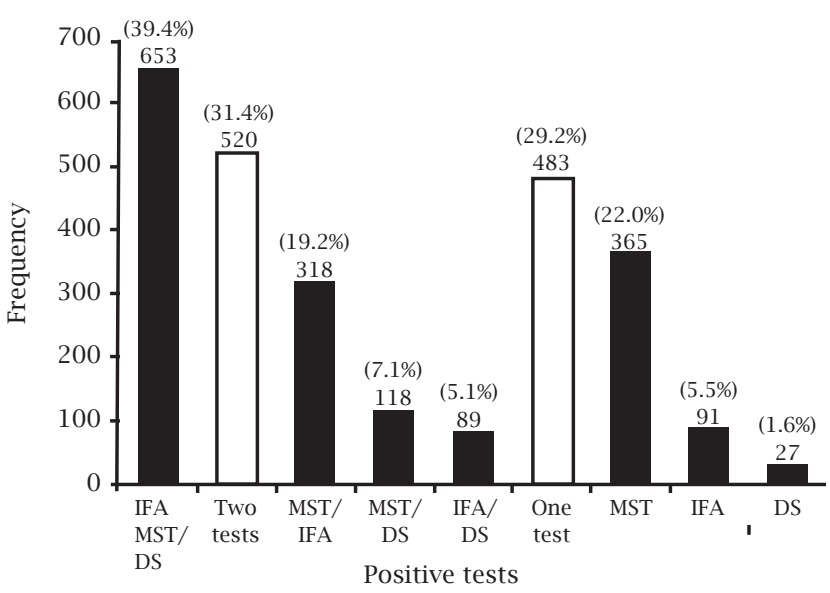

MST, Montenegro skin test; DS, direct search; IFA, indirect immunofluorescent assay.

When IFA and MST tests results were analyzed with regard to lesion-evolution time (Table 2), IFA positiveness was higher among patients with a lesion-evolution time of $\leq 2$ months, with $71.1 \%$ of patients manifesting titers of $40-80$ ( $\mathrm{p}=$ 0.0000 ). Most patients (57.3\%) with a positive MST result had $\mathrm{a} \leq 2$ months lesion-evolution time and a $>10 \mathrm{~mm}$ induration diameter (54.1\%). However, there was no association between induration diameter and lesion-evolution time $(\mathrm{p}=0.7916)$.
The age bracket most affected by ACL was between 15 and 49 years $(66.1 \%)$. Variables associated with the above age bracket were: male $(\mathrm{p}=0.00000)$; lesion-evolution time $\leq 2$ months $(\mathrm{p}=0.00000)$; residence in an urban area $(\mathrm{p}=0.00175)$; cutaneous form of the disease $(\mathrm{p}=0.00000)$ (Table 3). In fact, most ACL patients were male (72.6\%), had lesions with less than two month duration $(53.9 \%)$ and featured the cutaneous form of the disease (88.0\%).

Table 2. Indirect immunofluorescent assay and Montenegro skin test results according to American cutaneous leishmaniasis evolution time in patients with positive diagnosis, Maringá- Paraná, Brazil, 1986-2005

\begin{tabular}{lccccc}
\hline & \multicolumn{5}{c}{ Lesion-evolution time (months) } \\
\hline & & $\leq 2$ & $>2$ & Total & p value \\
\hline \multirow{2}{*}{ IFA (titles) } & $40-80$ & 463 & 321 & 784 & \\
& $\geq 160$ & 208 & 111 & 319 & 0.0000 \\
\cline { 2 - 6 } Total & & 671 & 432 & 1,103 & \\
\multirow{2}{*}{ MST (mm) } & 5 a 10 & 362 & 227 & 589 & \multirow{2}{*}{0.7916} \\
& $>10$ & 425 & 360 & 785 & \\
\multirow{2}{*}{ Total } & & 787 & 587 & 1,374 & \\
\end{tabular}

IFA, indirect immunofluorescent; MST, Montenegro skin test; $\chi^{2}$ test.

Table 3. Patients with positive American cutaneous leishmaniasis laboratory diagnosis according to gender, lesion evolution time, location of residence and form of the disease, Maringá- Paraná, Brazil, 1986-2005

\begin{tabular}{|c|c|c|c|c|c|}
\hline \multirow[t]{2}{*}{ Variable } & \multicolumn{4}{|c|}{ Age } & \multirow{2}{*}{$\mathbf{p}^{*}$} \\
\hline & $0-14$ & $15-9$ & $>50$ & Total & \\
\hline \multicolumn{6}{|l|}{ Sex } \\
\hline Male & 61 & 842 & 297 & 1,200 & \multirow{3}{*}{0.00000} \\
\hline Female & 59 & 252 & 143 & 454 & \\
\hline Total & 120 & 1,094 & 440 & 1,654 & \\
\hline \multicolumn{6}{|c|}{$\begin{array}{l}\text { Lesion-evolution } \\
\text { time }\end{array}$} \\
\hline$\leq 2$ months & 83 & 629 & 180 & 892 & \multirow{3}{*}{0.00000} \\
\hline$\geq 2$ months & 37 & 465 & 260 & 762 & \\
\hline Total & 120 & 1,094 & 440 & 1,654 & \\
\hline \multicolumn{6}{|l|}{ Residence } \\
\hline Urban & 75 & 769 & 318 & 1,132 & \multirow{3}{*}{0.00175} \\
\hline Rural & 73 & 317 & 118 & 508 & \\
\hline Total & 118 & 1,086 & 436 & 1,640 & \\
\hline \multicolumn{6}{|l|}{ Form } \\
\hline Cutaneous & 118 & 1,003 & 329 & 1,450 & \multirow{3}{*}{0.00000} \\
\hline Mucosal & 1 & 87 & 110 & 198 & \\
\hline Total & 119 & 1,090 & 439 & 1,648 & \\
\hline
\end{tabular}

${ }^{*} \chi^{2}$ Mantel-Haenszel test. 


\section{DISCUSSION}

ACL is a public health problem in Brazil and in the state of Paraná, Brazil, where the first case of the disease was reported in 1917. It has been on the increase since $1980 .{ }^{10}$

In current study, MST was positive in $92.3 \%$, IFA in $70.0 \%$ and DS in $65.1 \%$ of ACL-suspected patients. Results of another study conducted in the same geographical area had very similar positiveness rates $(91.1 \%$ for MST, $64.4 \%$ for IFA and $59.4 \%$ for DS) ${ }^{18}$ Barreto et al. obtained a $54.4 \%$ positiveness rate for IFA in patients with active lesions, ${ }^{2}$ while Pappas et al. obtained 82.0\%. ${ }^{19}$ Moreover, Szargiki et al., using parasitological methods, detected $79.3 \%$ of the patients with clinical diagnosis, and demonstrated a $95 \%$ sensitivity with serological methods for homologous antigens. ${ }^{20}$ However, when IFA and MST positiveness rates were analyzed for diseased patients, rates reached $83.9 \%$ and $91.6 \%$, respectively.

Since the current analysis showed that no consistency among the three laboratory tests studied for ACL diagnosis, one could suggest that the simultaneous use of two or more tests is the most reliable way of successfully identifying ACL cases. Silveira et al. also found that the association of techniques conferred greater reliability to the ACL laboratory diagnosis and suggested that MST should always be associated with DS or IFA techniques. ${ }^{18}$ In fact, it is interesting to note that $39.4 \%$ of patients in the present study had positive results for the three laboratory tests and $31.4 \%$ had positive results for at least two of the three tests.

It was also observed that most patients with positive IFA or MST results had a lesion evolution time of less than two months. Results reinforce the importance of these tests for patients with recent lesions and are in accordance with data reported by Silveira et al. who found that up to $96.3 \%$ of patients with positive MST and IFA results showed disease evolution of up to one month. ${ }^{18}$

Higher frequency of ACL cases among males between the ages of 15 and 49 has also been reported in other states. $^{21-23}$ The current study showed that most patients had the cutaneous form of the disease, lived in urban environments and acquired ACL during work or leisure activities. It has been observed that in Latin America and in Brazil a significant decrease in forest areas has led to an ACL increase in urban regions which, consequently, requires new methods of disease control. ${ }^{24-25}$ On the other hand, the understanding of ACL transmission dynamics and the relationship between the environmental and socio-economic factors that contribute to its maintenance are mandatory. ${ }^{26}$

The predominance of cases among males, the low number of cases among those under 14 years, and most people acquiring the disease during work activities coincides with the characteristics of the social and economic model of the southern region of Brazil and of the state of Paraná. Migration to urban centers has been on the rise in the state of Paraná where the lack of formal labor has forced individuals to seek occasional work on sugarcane, soya bean and wheat plantations, and in small agro-industrial companies. Through this process, males, hailing from the towns, return to the countryside and reduce and degrade forest environments, forcing wild animals into the urban areas and thereby creating urban foci of the disease. ${ }^{27}$ The above description of ACL in the state of Paraná coincides with that reported by Monteiro et al. in which most ACL cases occur within the green belts of the town and cities in which fragments of modified native forest still exists. ${ }^{28}$ This factor coupled to a density of phlebotomies and to the free circulation of the wild animal reservoirs, is the basis for ACL persistence in the state.

\section{CONCLUSION}

This study showed that the majority of patients had the cutaneous form of ACL, lived in urban environments and acquired it during work or leisure activities, with predominance of cases in the male population, and low number of cases among under 14-year-old individuals. The persistence of ACL, with the characteristics of an urban disease but with innumerable cases associated with the rural environment, is a challenge. In this context, the identification of the disease is important not only for its early and correct treatment but as a general guide for health public policy in its control. Results of the current investigation suggest a combination of laboratorial tests involving the association of at least two types of tests, of which one should be the MST, for adequate identification of ACL.

\section{REFERENCES}

1. Schubach A, Cuzzi-Maya T, Oliveira AV et al. Leishmanial antigens in the diagnosis of active lesions and ancient scars of American Tegumentary Leishmaniasis Patients. Mem Inst Osvaldo Cruz 2001; 96(7):987-96.

2. Barreto AC, Cuba CAC, Marsden PD et al. Características epidemiológicas da leishmaniose tegumentar americana em uma região endêmica do Estado da Bahia, Brasil. I. Leishmaniose humana. Boletín de la Oficina Sanitaria Panamericana 1981; 90(5):415-23.

3. Mendonça MG, de Brito ME, Rodrigues EH et al. Persistence of Leishmania parasites in scars after clinical cure of American cutaneous leishmaniasis: is there a sterile cure? J Infect Dis. 2004; 189(6):1018-23.

4. Marsden PD. Mucosal leishmaniasis ("Espundia”, Escomel, 1911). Trans R Soc Trop. Med Hyg. 1986; 80(6):859-76.

5. Guevara P, Ramírez JL, Rojas E et al. Leishmania braziliensis in blood 30 years after cure. Lancet 1993; 341(8856):1341.

6. Rodrigues AM, Hueb M, Santos TARR et al. Factors associated with treatment failure of cutaneous leishmaniasis with meglumine antimoniate. Rev Soc Bras Med Trop. 2006; 39(2):139-45.

7. Walton BC. Evaluation of Chemoterapy of American Cutaneous Leishmaniasis by the Indirect Florescent Antibody Test. Am J Trop Med Hyg. 1980; 29(5):747-52. 
8. de Oliveira CP, Junger J, do Espírito SSPF et al. Haematogenous dissemination of Leishmania (Viannia) braziliensis in human American tegumentary leishmaniasis. Trans R Soc Trop Med Hyg. 2006; 100(12):1112-17.

9. Arias J, Beltran F, Desjeux P, Walton B. Epidemiologia y control de la leishmaniasis en las Americas, por pais o territorio. Washington: OPAS. Cuaderno Técnico 1996: 44:1-52.

10. Brasil. Ministério da Saúde. Manual de vigilância da leishmaniose tegumentar americana. Ministério da Saúde; Brasília, 2007.

11. Teodoro U, Alberton D, Kühl JB et al. Ecology of Lutzomyia (Nyssomyia) whitmani in an urban area in Brazil. Rev Saúde Pública 2003; 37(5):651-56.

12. Venazzi EA, Roberto AC, Barbosa-Tessmann IP et al. Detection of Leishmania (Viannia) DNA in blood from patients with American cutaneous leishmaniasis. Exp Parasitol. 2007; 115(4):399-02.

13. Vega-López F. Diagnosis of cutaneous leishmaniasis. Curr Opin Infec Dis. 2003; 16(2):97-01.

14. Faber WR, Oskam L, van Gool T et al. Value diagnostic techniques for cutaneous leishmaniasis. J Am Acad Dermatol. 2003; 49(1):70-4.

15. Brasil. Ministério da Saúde. Leishmaniose tegumentar, distribuição de casos confirmados por unidade federada. Brasil, 1980 a 2005. Available at: http://portal.saude.gov.br/portal/ saude/profissional/visualizar_texto.cfm?idtxt=25340.Accessed September 16, 2007.

16. Reed SG, Badaró R. Leishmanioses. In: Ferreira AW, Ávila SLM. eds. Diagnóstico laboratorial das principais doenças infecciosas e auto-imunes. Rio de Janeiro: Guanabara-Koogan, 2001.

17. Landis JR, Koch GG. The measurement of observer agreement for categorical date. Biometrics 1977; 33(1):159-74.

18. Silveira TGV, Arraes SMA, Bertolini DA et al. Observações sobre o Diagnóstico Laboratorial e a Epidemiologia da Leishmaniose Tegumentar no Estado do Paraná. Rev Soc Bras Med Trop. 1999; 32(4):413-23.
19. Pappas MG, McGreevy PB, Hajkowski R et al. Evaluation of promastigote and amastigote antigens in the indirect fluorescent antibody test for American cutaneous leishmaniasis. Am J Trop Med Hyg. 1983; 32(6):1260-67.

20. Szargiki R, Castro EA, Luz L et al. Comparison of Serological and Parasitological Methods for Cutaneous Leishmaniasis Diagnosis in the State of Paraná, Brazil. Braz J Infect Dis. 2009; 13(1):47-52.

21. Nunes AG, Paula EV, Teodoro R et al. Epidemiological aspects of American tegumentary leishmaniasis in Varzelândia, Minas Gerais, Brazil. Cad Saúde Pública 2006; 22(6):1343-47.

22. Salomón OD, Sosa-Estani S, Ramos K et al. Tegumentary leishmaniasis outbreak in Bella Vista City, Corrientes, Argentina during 2003. Mem Inst Osvaldo Cruz 2006; 101(7):767-74.

23. Jorquera A, Ledezma E, Souza L et al. Epidemiologic characterization of american cutaneous leishmaniasis in an endemic region of eastern Venezuela. Am J Trop Med Hyg. 1998; 58(5):589-93.

24. Campbell-Lendrum D, Dujardin J-P, Martinez E et al. Domestic and Peridomestic Transmission of American Cutaneous Leishmaniasis: Changing Epidemiological Patterns Present New Control Opportunities. Mem Inst Oswaldo Cruz, 2001; 96(2):159-62.

25. Kroeger A, Avila EV, Morison L. Insecticide impregnated curtains to control domestic transmission of cutaneous leishmaniasis in Venezuela: cluster randomised trial. BMJ 2002; 325(7):810-13.

26. Machado-Coelho GL, Assunção R, Mayrink W et al. American Cutaneous Leishmaniasis in southeast Brazil: space-time clustering. Int J Epidemiol. 1999; 28(5):982-9.

27. Arraes SM, Marini MT, Martello D et al. Serological investigation of subclinical cutaneous leishmaniasis cases following an outbreak in an endemic area. Rev Soc Bras Med Trop. 2008; 41(2):205-08.

28. Monteiro WM, Neitzke HC, Lonardoni MV et al. Geographic distribution and epidemiological features of American tegumentary leishmaniasis in old rural settlements in Paraná State, Southern Brazil. Cad Saúde Pública 2008; 24(6):1291-303. 